\title{
Formação inicial docente e a prática pedagógica no estágio supervisionado: da marafunda euro-colonialista à ginga afrodiaspórica em resistência
}

\author{
Initial teacher training and the pedagogical practice in the supervised internship: \\ from Euro-colonialist marafunda to Afrodiasporic ginga in resistance
}

\author{
Rodrigo Batista Lobato \\ Doutor em Geografia pela UFRJ \\ Instituto Federal Fluminense / Universidade Veiga de Almeida \\ rodrigolobato.geo@gmail.com
}

Resumo: $O$ presente artigo materializa a reflexão sobre o processo formativo docente de licenciandos na fase de estágio supervisionado, bem como, discentes bolsistas da CAPES no PIBID, em contato com o discurso colonialista existente nos currículos e livros didáticos e seu contraponto às Leis 10.639/2003 e $11.645 / 2008$. As atividades ocorreram no Colégio Estadual Antônio Prado Júnior (CEAPJ) - em contexto pandêmico de Covid19, logo processos de ensino-aprendizagem virtualizados. Nosso objetivo foi partir dos discursos decoloniais e afrodiaspóricos, ancorados em saberes advindos dos provérbios africanos e do pensamento freiriano, propondo aos licenciandos um olhar autocrítico sobre suas formações e a permanência de discursos euro-colonialistas. A metodologia utilizada para atingir o objetivo articulou a escuta do Outro e a práxis embrionária de ruptura com a marafunda epistemológica colonialista. Para alicerçar este caminho de reflexão foram utilizados os conhecimentos geográficos e históricos analisando o currículo proposto pela Secretaria de Educação do Estado do Rio de Janeiro (Seeduc-RJ) e os livros didáticos enviados à escola pelo PNLD, a partir da temática do Egito antigo.

Palavras-chave: Formação docente; Decolonialismo; Saberes afrodiaspóricos; Episteme euro-colonialista; Estágio Supervisionado.
Giovanni Codeça Silva

Doutor em Letras Neolatinas/UFRJ Seeduc - RJ / Universidade Veiga de Almeida giovanni.codeca@uva.br

Abstract: The present article materializes the reflection about the teaching formation process of undergraduate students in the supervised internship phase, as well as students with CAPES scholarship in PIBID, in contact with the colonialist discourse existing in the curriculums and textbooks and its counterpoint to the Laws $10.639 / 2003$ and $11.645 / 2008$. The activities took place at Colégio Estadual Antônio Prado Júnior (CEAPJ) - in the pandemic context of Covid-19, thus virtualized teaching-learning processes. Our goal was to start from decolonial and Afro-diasporic discourses, anchored in knowledge coming from African proverbs and Freirean thought, proposing to the undergraduates a self-critical look at their formations and the permanence of Euro-colonialist discourses. The methodology used to reach the goal articulated the listening to the Other and the embryonic praxis of rupture with the colonialist epistemological mess. To support this reflection path, the geographic and historical knowledge was used, analyzing the curriculum proposed by the Secretary of Education of the State of Rio de Janeiro (Seeduc-RJ) and the textbooks sent to the school by the PNLD, based on the ancient Egypt theme.

Keywords: Teacher Training; Decolonialism; Afrodiasporic Knowledge; Euro-colonialist Episteme; Supervised Internship. 


\section{Não se pode esconder a fumaça se você acendeu o fogo}

A educação é um caminho para a transformação da sociedade. Definitivamente não se trata do caminho mais rápido, e tampouco os punhos cerrados são atalhos para essa transformação. Definitivamente não se trata apenas de uma política pública, pois os discursos verborrágicos são construídos sobre o assentamento euro-colonial de uma sociedade racista e desigual. Mas a educação é certamente aquela que lança suas raízes aos céus - como um Baobá, e, assim, se prolonga para além de si mesma. É um caminho lento, pois avança quando a consciência é crítica e retroage quando é meramente um discurso vazio. É um caminho político, pois educar é uma ação política de auto-libertação.

As Leis 10.639/2003 e 11.645/2008 tratam e ampliam, respectivamente, a questão do ensino da história e da cultura de povos africanos, afrodescendentes e indígenas na educação brasileira. Lei fundamentalmente necessária, que juntamente com a Lei 12.711/2012 (Lei de cotas), vem transformando a realidade social brasileira - uma caminhada lenta e repleta de preconceitos. Essas leis que visam a redução da desigualdade social e o combate à permanência do passado escravista e escravagista em nossa sociedade, são o sinal de fumaça do fogo que ainda está por vir. Não o fogo que destrói e consome todos em sua volta, mas o fogo que transforma matérias e vida, que permite a existência e o recomeço. Pensar a educação como ação política e transformadora numa sociedade como a brasileira, é buscar abandonar o lugar comum, é uma necessidade de romper com a marafunda ${ }^{1}$ euro-colonialista, que estruturou condições de poder material objetivas e imateriais subjetivas.

Assim, este texto apresenta o diálogo estabelecido a partir do "chão", virtualizado, da escola - Colégio Estadual Antônio Prado Júnior (CEAPJ), - entre os licenciandos de diferentes Universidades da cidade do Rio de Janeiro, que buscam cumprir o estágio supervisionado obrigatório de 400h; os licenciandos que participam das atividades do Programa Institucional de Bolsas de Iniciação à Docência (PIBID) da CAPES licenciandos dos cursos de Geografia e História da Universidade Veiga de Almeida

\footnotetext{
${ }^{1}$ Marafunda significa uma mistura sem orientação, confusa. Assumimos o sentido proposto por Joel Rufino de marafunda colonial como uma ferida traumática aberta, exposta, não curada. Porém, acrescentamos a marafunda colonialista a epistemologia eurocêntrica, pois compreendemos que este processo possui uma historicidade iniciada na construção eurocêntrica que desloca a experiência africana para fora do campo do conhecimento. Assim propomos a marafunda euro-colonialista como toda epistemologia discursiva criada com base eurocêntrica e perpetuada no colonialismo que visa enunciar o aprisionamento do pensamento disruptivo decolonial.
} 
(UVA) - com os docentes que realizam a supervisão/preceptoria no CEAPJ e a supervisão institucional da UVA. O CEAPJ está situado na Praça da Bandeira, no centro da cidade do Rio de Janeiro. Por ser uma escola central e ao mesmo tempo próxima de comunidades marginalizadas pelo poder público, os discentes formam claramente dois conjuntos: um primeiro grupo de discentes que residem distante da escola e a escolhem por sua centralidade; e o segundo grupo de discentes que residem nas comunidades do entorno da escola.

O CEAPJ é uma escola pública tradicional que integra a rede de escolas estaduais sob a coordenação da regional VI e parte da Seeduc-RJ. A escola foi criada em 1963 no governo de Carlos Lacerda com foco na educação básica, porém logo passou a abrigar diferentes cursos técnicos. A escola passou a ser conhecida por prestar um serviço de educação de excelência, o que passou a atrair discentes e pais de diferentes regiões da cidade, aumentando assim a disputa por suas vagas. O nome da escola se tornou uma tradição, mas ao longo dos anos passou a sofrer com a depreciação de sua estrutura física, como toda a rede estadual de ensino. As ausências de políticas públicas afetaram decisivamente a escola e na atualidade resiste com a formação geral nos três turnos, o Ensino de Jovens e Adultos (EJA) e o curso de formação de Guias de Turismo concomitante ao Ensino Médio noturno.

Atualmente o CEAPJ atrai muitos licenciandos para realização do estágio supervisionado. Tal atração é alvo de mapeamento realizado pela gestão da unidade escolar. O que justifica esta atração são três motivos que se alternam, mas se mantém comum ao logo dos anos: a centralidade da escola em relação aos meios de transporte, as Universidades e suas residências; os projetos desenvolvidos pela escola que incluem visitas técnicas e saídas para outros espaços não escolares em diversas disciplinas; e a atuação de divulgação de outros colegas licenciandos que realizaram as atividades de estágio supervisionado na escola e sinalizam como positiva a experiência para aqueles que buscam uma escola para estagiar.

Os discentes de licenciatura da Universidade Veiga de Almeida (UVA) que realizam o PIBID/CAPES participam de um projeto interdisciplinar de Geografia e História aprovado no último edital de bolsas em 2020. Nesse projeto um dos objetivos centrais estava na investigação de como as identidades sociais são tensionadas a partir dos saberes escolares, utilizando para tal a compreensão de categorias (SANTOS, 2008) e conceitos (KOSELLECK, 2003). O projeto interdisciplinar teve por base a interseção entre os campos de saberes (BOURDIEU, 1989) especificando alguns caminhos de 
interpretação como a noção de território (SOUZA, 2012), o lugar (SANTOS, 2012), a identificação cultural (HALL, 1997), a localidade histórica (FONSECA, 2013) e a memória (CANDAU, 2011).

O ano de 2020 teve início com o planejamento das atividades no mês de fevereiro, até então um ano letivo presencial. Os licenciandos de Geografia e História - do estágio supervisionado e do Pibid - participaram do planejamento das atividades e ainda no mês de fevereiro das rodas de conversas na qual os docentes das disciplinas discutiram internamente como as questões principais serão abordadas e posteriormente ocorreu a discussão na grande área de humanas, ampliada com a participação da área de linguagens. Neste momento foi possível perceber que as trajetórias de cada um deles era bem diferente em relação as temáticas ligadas às Leis 10.639 e 11.645. Seria necessário promover uma troca de conhecimentos, experiências e vivências para que todos pudessem participar ativamente. Assim, foi construída uma proposta de formação junto aos professores orientadores de estágio supervisionado de formação ligada a história e cultura africana, afrodiaspórica e dos povos originários a partir de uma perspectiva decolonial. Este texto materializa essa experiência de temáticas dialogadas e que não estavam inclusas em suas formações ou haviam sido trabalhadas de forma normatizada pela visão eurocêntrica ou "romantizada" em relação aos saberes escolares. Em todos os aspectos bem distante da práxis escolar e do pensamento crítico e reflexivo sobre o Currículo Mínimo do Estado e da BNCC.

As temáticas dos diálogos buscaram apontar caminhos complementares à formação dos licenciandos, ou seja, estabelecer pontos de cruzo (RUFINO, 2019) entre duas realidades distintas e paralelas: a primeira, centrada no contato entre a episteme euro-colonialista (presente em suas formações acadêmicas) e os saberes afrodiaspóricos (presente nas comunidades onde atuam); e a segunda, o conhecimento teórico adquirido em suas formações e o saber prático riscado no chão da sala de aula. A centelha deste cruzo, pretende acender o candeeiro e iluminar outras possibilidades de leitura de mundo para além do caminho traçado pela Base Nacional Comum Curricular (BNCC), pois o pressuposto apresentado aos licenciandos, foi o do chão da sala de aula como um campo aberto de aprendizagem significativa e contínua entre docentes e discentes.

A educação é permanente não porque certa linha ideológica ou certa posição política ou certo interesse econômico o exijam. A educação é permanente na razão, de um lado, da finitude do ser humano, de outro, da consciência que ele 
tem de sua finitude. Mais ainda, pelo fato de, ao longo da história, ter incorporado à sua natureza não apenas saber que vivia, mas saber que sabia e, assim, saber que podia saber mais. A educação e a formação permanente se fundam aí (FREIRE, 2001: 12).

Porém em março, iniciando a segunda quinzena do mês, a pandemia de Covid-19 obrigou a suspensão das aulas presenciais, uma decisão correta por parte da Seeduc-RJ. Com o retorno das aulas de forma virtualizada através do Google Classroom o estágio supervisionado e as ações do Pibid foram organizadas dentro das possibilidades que o ensino remoto emergencial nos permitiu. Desta forma foi necessário adaptar todo o planejamento o que ocasionou a junção das ações dos estagiários e dos pibidianos, garantindo assim que as ações ocorressem sem maiores prejuízos, além dos causados por esta nova ambiência. Assim este artigo visa apresentar o processo de formação docente para desconstrução do pensamento decolonial, tanto no estágio supervisionado como no PIBID, realizado por licenciandos de diferentes Universidades em ação no "chão" do CEAPJ - virtualizado devido à pandemia de Covid-19. Os caminhos metodológicos deste artigo seguem na contramão das estruturas científicas euro-colonialistas, assumimos a forma de construção dos saberes africanos, introduzidos por provérbios que apresentam o caminho para reflexão, porém sem determinar seu ponto de chegada. Estas jornadas são do Outro em mim e do Eu com o Outro, aprofundadas pela dinâmica do tempo formativo de cada um e sua percepção espacial dos elementos que o cercam. Apresentamos ao longo do texto os saberes e fazeres caminhando lado a lado, possuindo também uma perspectiva freireana, de uma educação dialógica, calcada na práxis reflexão e ação.

\section{Como a ferida inflama o dedo, o pensamento inflama a mente}

A história da constituição de nossa sociedade, tem fundamento no colonialismo português e em seu contato com as matrizes tupi e africana (RIBEIRO, 2002). Toda a fragilidade e potência do Império colonial lusitano, deixaram traços constitutivos que alicerçaram as relações sociais, econômicas e de poder até os dias de hoje.

A sociedade e a cultura brasileiras são conformadas como variantes da versão lusitana da tradição civilizatória europeia ocidental, diferenciadas por 
coloridos herdados dos índios americanos e dos negros africanos. O Brasil emerge, assim como um renovo mutante, remarcado de características próprias, mas atado genesicamente à matriz portuguesa, cujas potencialidades insuspeitadas de ser e de crescer só aqui se realizaram completamente (RIBEIRO, 2002: 20).

Não se trata de uma justificativa que venha eximir a sociedade brasileira de assumir sua responsabilidade sobre a atual condição, ao contrário, é uma explicação de parte importante e constitutiva da origem de nossos fundamentos sociais. Para compreendermos nosso complexo social é preciso compreender os mecanismos de permanência desta marafunda euro-colonialista, que foi (re)construída para ser imobilizante e criar um ebó insuperável, garantindo assim, as desigualdades sociais.

Logo, o primeiro convite realizado aos licenciandos que integravam o grupo sob supervisão/preceptoria ${ }^{2}$, foi o de abandonar, inicialmente, a ideia de habilidades, competências e conteúdos contidos na BNCC. A proposta foi iniciar as atividades a partir de uma reflexão metodológica riscada nos "chãos de saberes". Um processo de leitura, compreensão e de imersão interior, tendo por base os estudos realizados por Luiz Rufino, no qual desenvolveu a compreensão de uma pedagogia das encruzilhadas, com especial atenção a potência expressa pelo cruzamento de saberes. Ou seja, compreendendo que conhecimentos e saberes são instâncias construídas no cruzamento de experiências e vivências. Sendo assim, reconhecendo a existência de diferentes processos educativos, oriundos de diferentes "chãos de saberes", onde a escola, a casa, a comunidade, a rua, entre tantos outros lugares se interseccionam com suas diferentes visões de mundo.

Imergir em si, buscando examinar em suas vivências como licenciandos, experiências ligadas à noção de práxis docente de autocrítica, experiências oriundas de saberes afrodiaspóricos, experiências associadas às epistemologias do sul, ou experiências de filosofias e pedagogias africanas e afrodescendentes. As respostas dos discentes revelaram feridas em suas formações, revelaram não apenas o desconhecimento, mas sobretudo, a visão inflamada pela marafunda euro-colonialista que

\footnotetext{
${ }^{2}$ Em 2020, em virtude da pandemia, o contato presencial no Colégio Antônio Prado Júnior foi reduzido. No mês de março contávamos com dezesseis estagiários, sendo, onze da Universidade Veiga de Almeida; três da Universidade Estácio de Sá, um da Universidade Federal Fluminense; e um da Universidade Federal do Rio de Janeiro. O início da pandemia de Covid fez o número de estagiários subir de dezesseis para cinquenta e oito, muitos sem a certeza de terem suas horas validadas devido às incertezas iniciais. O número de estagiários foi acrescido por dezesseis novos licenciandos, em outubro, oriundos do PIBID, porém, neste momento do ano já haviam se desligado do estágio onze discentes. Chegaram ao final sessenta e três discentes, sendo, quarenta e sete estagiários, e dezesseis pibidianos.
} 
imobiliza a formulação de pensamentos e ações autônomas. O primeiro problema estava posto: Como propor ações fora da lógica euro-colonialista, se o pensamento estava fundado sobre esta visão de mundo?

Logo a proposta buscou essa autorreflexão, um olhar para dentro do Eu docente, constituído numa sociedade racista e formado pelas leituras euro-colonialistas. Retornar algumas leituras, desnaturalizar alguns conceitos, perceber como seu campo de formação se constituiu sob a lógica de um contexto civilizatório colonial. Iniciado desde o invisibilizamento da relação entre a espécie sapiens do gênero homo ter se originado na África e, a partir de lá, ter conquistado terras e dominado o mundo, por ser o mais apto e evoluído, passando pelo apagamento das civilizações antigas africanas, seus saberes e suas histórias, com o não reconhecimento da oralidade como instrumento de força social e chegando ao deslocamento do Egito e sua sociedade, quase sempre aproximado da Ásia - região da bacia dos Rios Tigres e Eufrates, ou , seu deslocamento para uma condição fenotípica branca, aproximando-o da Europa.

A partir desse mergulho iniciamos o segundo movimento que consistiu em acionar o pensamento crítico, através da problematização: se existem e persistem diferentes processos educativos constituídos a partir de diferentes "chãos escolares", quem, o quê, e por quê alguns conhecimentos são hierarquizados como maiores e essenciais e outros são considerados menores e desprezados? Um indicativo de resposta se encontra nas palavras de Paulo Freire,

mas a gente ainda tem que perguntar em favor de que conhecer e, portanto, contra que conhecer; em favor de quem conhecer e contra quem conhecer. Essas perguntas que a gente se faz enquanto educadores, ao lado do conhecimento que é sempre a educação, nos levam à confirmação de outra obviedade que é a da natureza política da educação. Quer dizer, a educação enquanto ato de conhecimento é também, por isso mesmo, um ato político (FREIRE, 1982: 97).

Educar-se é uma ação política, educar é uma ação política. Não por outro motivo a educação brasileira encontra seus descaminhos em políticas públicas e em sua própria episteme, ambas objetivando a reprodução do ordenamento euro-colonialista, e por isso, uma marafunda, que impossibilita a construção de caminhos autônomos para educação nacional. Esta construção tem ajudado a perpetuar desigualdades sociais e o poder 
material e simbólico nas mãos dos donos do poder (FAORO, 2012), sem grandes alterações desde o projeto colonizador português até os dias de hoje e seus novos mecanismos de coesão e coerção social. Este processo histórico dista de uma história linear, uma teoria de dominação racionalmente desenhada e controlada, ao contrário, em alguns momentos esta ordem se vê ameaça, e nestes momentos são colocados em curso todos os dispositivos necessários para que o bloco histórico no poder se perpetue.

\section{Quando teias de aranha se juntam, elas podem amarrar um leão}

Ainda neste processo de olhar para o Eu docente, propomos adentrar à mata do pensamento decolonial, sob a perspectiva do ensino de Geografia e História. De uma forma geral, o ensino chegou ao Brasil dentro do contexto do projeto colonialista português, e sob esta perspectiva, encontramos um dos pontos de eficiência do processo de dominação lusitana. Se por muitas vezes, a colonização, embora centralizada na Coroa portuguesa tenha deixado o colono abandonado à própria sorte, em momento algum a educação das elites coloniais não seguiu uma orientação clara - educar na metrópole para pensar como a metrópole. Diferente do projeto colonizador espanhol, que desde muito cedo, permitiu o desenvolvimento de um ensino em terras além mar, o projeto colonizador português aguçou a distância entre a elite colonial e os negros da terra e de África. Reside neste ponto, uma possibilidade de leitura dos processos de formação da elite brasileira, forjada em terras portuguesas com sentimento de não pertencimento e estranhamento ${ }^{3}$, em relação a sua matriz luso-européia, alimentando um sentimento de superioridade, desprezo e desumanidade em relação à índios e negros.

Com a transferência da Família Real Portuguesa para o Brasil, foi necessário transformar a colônia em sede do Império Ultramarino, neste momento, o ensino passa por uma nova orientação, e assim, modelos educacionais passam a ser transplantados para a capital do Império, o principal deles o modelo francês. Nesta fase também, ocorre na Europa a

\footnotetext{
3 O mal-estar da elite colonial brasileira com sua matriz lusa-europeia se perpetuou na formação da sociedade brasileira. Afirmada como matriz relevante em relação às matrizes tupi e africana - afinal sempre foi nossa ligação com a Europa, a mesma matriz lusa foi tratada como uma cultura menor em relação aos ingleses e principalmente em relação à cultura francesa e alemã. Esta forma de perceber a matriz lusa em paralaxe guarda origem na própria constituição social do povo português ao negar e apagar sua origem moura, logo, muçulmana e negra, tal qual foi realizado também por franceses. Porém os mouros se espalharam por boa parte da Europa, sendo retratado inclusive na peça A tragédia de Otelo, o Mouro de Veneza (1604), de William Shakespeare (1582-1616).
} 
consolidação das ciências modernas disciplinares. A Geografia moderna fundada na Alemanha com Alexander von Humboldt (1769-1859) e Carl Ritter (1779-1859) assumiu como pressupostos a descrição, o empirismo, a observação, a intuição e a síntese. Foi sob estes pressupostos que a Geografia disciplinar desembarcou no Brasil.

A geografia escolar que passou a ser ensinada no Brasil, mas não só ela, reproduziu quase que na íntegra o que estava sendo estudado nos liceus franceses. "Transplantaram", sem expressivas alterações, tanto a forma como o conteúdo que caracterizavam a geografia escolar. Acreditamos, no entanto, que esta alardeada "transplantação" deva ser objeto de um estudo mais aprofundado, pois acreditamos que as especificidades sócio-históricas brasileiras exigiram que adaptações ou reelaborações fossem realizadas a partir do modelo importado (ROCHA, 1997: 2).

A História como disciplina moderna também se inscreve no momento histórico do século XIX . Apesar do pontapé inicial do italiano Giambattista Vivo (1688-1744), foi com o alemão Leopold von Ranke (1795-1886) que a Ciência histórica assumiu os pressupostos do positivismo, com ênfase no estudo dos eventos, tendo por base a objetividade, e assim um resgate do passado.

O ensino de História se destaca por mudanças marcantes em sua trajetória escolar que a caracterizavam, até recentemente, como um estudo mnemônico sobre um passado criado para sedimentar uma origem branca e cristã, apresentada por uma sucessão cronológica de realização de "grandes homens" para uma 'nova' disciplina constituída sob paradigmas metodológicos que buscam incorporar a multiplicidade de sujeitos construtores da nação brasileira e da história mundial. No Brasil, a História escolar, sob diferentes denominações, História Universal ou História da Civilização, História do Brasil ou História Pátria..., são indicativas de um percurso de mudanças quanto aos objetivos, conteúdos e práticas educacionais do século XIX aos dias atuais (BITTENCOURT, 2018: 197).

A partir das citações que tratam do ensino das disciplinas no Brasil, é possível perceber como tanto o ensino de Geografia quanto o de História no Brasil se constituíram por um caráter colonialista do saber. Mesmo após o processo de independência, se 
perpetuando na implementação da República, o colonialismo sobreviveu. De acordo com Oliveira e Candeu (2010: 18), na forma de colonialidade, o ensino chega às raízes profundas de um povo e sobrevive apesar da descolonização ou da emancipação das colônias latino-americanas, asiáticas e africanas nos séculos XIX e XX.

Tais marcas dessa colonialidade do saber do ensino de Geografia e História, se mostram com encontros e desencontros dessas duas ciências humanas, que fazem parte do currículo da Educação Básica, tanto que ambas já foram suprimidas, tornando-se a disciplina Estudos Sociais. Por sua vez, Quijano (2007) faz distinção entre colonialismo e colonialidade, e considera que ambos conceitos estejam relacionados, porém, não são a mesma coisa, pois colonialismo trata dos padrões de dominação e exploração. Significa dizer que colonianismo para Quijano (2007: 93), é o controle da autoridade política, dos recursos de produção e do trabalho de uma população determinada possui diferente identidade e as suas sedes centrais estão, além disso, em outra jurisdição territorial.

Para o mesmo autor (QUIJANO, 2007: 93), a colonialidade provou ser, nos últimos 500 anos, mais profunda e duradoura que o colonialismo. Porém, sem dúvida, foi forjado dentro deste, e mais ainda, sem ele não teria podido ser imposta à intersubjetividade de modo tão enraizado e prolongado. Sobre esta colonialidade, a partir do grupo Modernidade/Colonialidade, têm-se três maneiras de apresentá-las, sendo colonialidades: do poder, do saber e do ser (QUIJANO, 2005, 2007; MIGNOLO, 2005; WALSH, 2005).

Mesmo que, conceitualmente diferentes, as mesmas possuem tramas nessa tessitura, em que, a colonialidade do poder, para Quijano (2007) estará calcado na subjetividade construído do subalternizado, fazendo pensar historicamente a noção de raça e assim, opera essa inferiorização de grupos não-europeus. Para o mesmo autor, a colonialidade do saber, pode ser compreendida como repressão de outras formas de produção do conhecimento não-europeu. Pega-se esses dois conceitos e faz-se essa análise com a ideia do ensino de História (BITENCOURT, 2018) e de Geografia (ROCHA, 1996), em que essa colonialidade do poder e do saber, no ensino e na escola, como sendo algo presente desde a sua institucionalização no século XIX.

A expressão 'colonialidade do poder' designa um processo fundamental de estruturação do sistema-mundo moderno/colonial, que articula os lugares periféricos da divisão internacional do trabalho com a hierarquia étnico-racial global e com a inscrição de migrantes do Terceiro Mundo na hierarquia étnico- 
racial das cidades metropolitanas globais. Os Estados-nação periféricos e os povos não-europeus vivem hoje sob o regime da "colonialidade global" imposto pelos Estados Unidos, através do Fundo Monetário Internacional, do Banco Mundial, do Pentágono e da OTAN. As zonas periféricas mantêm-se numa situação colonial, ainda que já não estejam sujeitas a uma administração colonial (GROSFOGUEL, 2008: 126).

Em outras palavras, ainda que já estejamos em uma modernidade líquida, como sugere Baumamn (2001), em pleno século XXI, e com esta perspectiva em processo de mudança na Educação, essa forma de pensar o ensino nas escolas, no qual é possível fazer uma analogia dos currículos atuais com o currículo Dente-de-Sabre do educador estadunidense Harold Benjamin (1893-1969) sob o pseudônimo J. Abner Peddiwell, em que fez uma metáfora com a educação nos Estados Unidos.

No Paleolítico, uma tribo desenvolveu um currículo educacional baseado nas necessidades de sobrevivência. Os jovens eram ensinados a espantar os tigres ente-de-sabre com tições incandescente, a abater cavalos de pelo comprido para se vestirem e a pescar com as próprias mãos.

No entanto, conforme os anos passavam, iniciou-se a Era Glacial e as necessidades de sobrevivência mudaram: os tigres morreram devido ao frio, os cavalos fugiram e os peixes desapareceram na água enlameada. Em seu lugar, apareceram enormes ursos ferozes que não se afugentavam com o fogo, antílopes que corriam velozes como o vento (os cavalos de pelo comprido eram desajeitados e lentos) e novos peixes se escondiam na água enlameada. A tribo depressa se deu conta que o currículo educacional deixará de ser relevante. Afugentar tigres, abater cavalos e apanhar peixes eram relíquias dos dias antigos. A tribo precisava agora, de aprender a fazer armadilhas para os ursos, a enganar os antílopes e a fazer redes de pesca.

Contudo, o sistema educativo da tribo declarou em tom altivo: Não sejam tontos... Nós não ensinamos a apanhar peixes para apanhar peixes, mas para desenvolver uma agilidade generalizada que nunca se poderia desenvolver através do simples treino de fazer redes. Não ensinamos a abater cavalos para abater cavalos; ensinamo-lo para desenvolver uma força generalizada que não se poderia obter fazendo uma coisa tão prosaica e especializada como é uma armadilha para enganar antílopes. Não ensinamos a afugentar tigres para 
afugentar tigres; ensinamo-lo para dar aquela coragem nobre (BENJAMIN, 1939).

A esse currículo defasado, questiona-se também que os mesmos não estão por reproduzir uma forma de ver o mundo pelo viés eurocêntrica. Assim, é possível verificar essas narrativas europeias nos livros didáticos, no qual pode-se trazer como exemplo do caso do Egito ou mesmo nos mapas mundí, com a Europa na centralidade do mundo. Todavia é imperioso esse debate decolonial para compreender esse fenômeno, que ainda permite esse discurso hegemônico dos países do Norte, em detrimento de outras formas de olhar e compreender o mundo. Mesmo que Cipriano Luckesi ao tratar do senso comum pedagógico, não tenha feito um paralelo com esse conceito de coloniadade do saber, cabenos fazer, de maneira que, esse senso comum pedagógico, ajuda a reforçar esse caráter da colonialidade do poder e do saber, visto que.

A ação docente tem sentido e significado. Já definimos anteriormente que, nas práticas humanas, quando não formulamos um sentido especifico para a ação que vamos realizar, adotamos um sentido dominante que se faz presente na sociedade e na cultura em que vivemos. Assim, se não buscarmos o sentido e o significado crítico, consciente e explícito da ação docente, seguimos o sentido e o significado dominante desse entendimento que se tornou senso comum. (LUCKESI, 1990: 97-98).

Dentro dessa perspectiva do senso comum pedagógico, como não tangenciar o uso e apropriação do livro didático na escola? Quando o docente usa-o como "bengala" para suas aulas, este poderá caracterizar um referencial europeu-hegemônicos de um pensamento pronto. Sobre isso, Luckesi (1990: 103), salienta qual o significado do livro didático na prática pedagógica escolar? No geral, ele tem sido assumido como uma "bíblia", ou seja, como um livro sagrado: tudo o que está escrito nele se assume como verdade. $\mathrm{O}$ autor trás questionamentos, pois, deve ser essa a atitude a ser assumida diante do livro didático? Será que ele não contém inverdades, reduções e desvios de conhecimentos?

Essa prática pedagógica e profissional, além de demonstrar despreparo, conota ainda esse senso comum pedagógico vai além dessa colonialidade do saber e do poder, mas também uma colonialidade do ser, tal como trata Walsh (2005), apontando esse 
colonialismo moderno de uma não-existência, pois, se trata de uma negação da outra pessoa. Ainda para Walsh (2006), essa negação trás problemas reais em torno da liberdade, do ser e da história do indivíduo subalternizado por uma violência epistêmica. Todavia, é possível ler em Cipriano Luckesi, no final do século XX essa crítica de uma subalternização reforçada pelo senso comum pedagógico, tendo no livro didático a única verdade para ser aplicada em sala de aula, em quê:

Baseado nessas considerações, não vamos cair no extremo oposto e dizer: 'então, não vale a pena utilizar livro didático nenhum'. Será que esta também não será uma posição ingênua e de senso comum? Já que os livros didáticos não contêm 'a' verdade, eles não devem ser utilizados! Ao contrário, eles podem e devem ser utilizados com criatividade, ultrapassando os elementos do senso comum. Ultrapassando, pela crítica, os próprios limites desses livros (LUCKESI, 1990: 103).

Seguir nessa contra-mão é buscar Pedagogias Decoloniais, empoderando os saberes e as epistemologias do Sul, resgatando o conhecimento e as histórias dos povos historicamente subalternizados e dando-lhe vozes e reforçando sua existência. Essa luta por uma Pedagogia Decolonial, pode ser apresentar por Bittencourt (2018: 142), pois de forma inédita, como fruto das lutas de movimentos sociais foram introduzidas a História da África e das culturas afro-brasileiras e a História dos indígenas por intermédio das leis 10.639/03 e 11.645/08. Para a mesma autora, essas leis estão em processo de integração em currículos ainda submetidos à lógica eurocêntrica, mas que anunciam uma formação política e cultural para o exercício de uma cidadania social com vistas a um convívio sem preconceitos e democrático. Assim percorremos uma primeira etapa composta por reflexões do Eu docente. Reflexões sobre os princípios formativos teóricos com a imersão no debate decolonial e na postura pedagógica objetivando tecer uma teia decolonial que supere a força deste leão que mantém cativa a maioria da sociedade brasileira.

\section{A orelha vai à escola todos os dias}


Após essa autorreflexão foi lançado como flecha o convite para comporem os grupos de pesquisa: Cartografia e seus multiletramentos: mapa, linguagem e narrativa; e Ensino e ação: memória e conservação na criação de novas paisagens culturais - Leis 10.639/2003 e 11.645/2008 objetivando conduzirem seus estágios e o PIBID sob uma dupla perspectiva: a primeira alinhada ao planejamento escolar para o qual confluem BNCC e Currículo Mínimo da Seeduc-RJ; o segundo desalinhado e transgressor da marafunda euro-colonialista que parte de uma perspectiva pedagógica afrodiaspórica reivindicando modos e fazeres comunitários tendo como interlocutores pensadores que seguem a temática africana e afrodiaspórica.

Logo, não basta ler e pensar, sob a perspectiva afrodiaspórica parida no ventre dos navios tumbeiros e criada em terra brasilis desigual, discriminatória e racista, é necessário se imbuir de toda ginga possível para esquivar das armadilhas colonialistas. Assim é preciso aprender a ouvir - como o provérbio africano - levar a orelha à escola cotidianamente - e assim, perceber que na dança da capoeira ou sob os atabaques, se dança junto, e nesta comunhão compreender a conectividade entre o provérbio africano e a escuta freiriana é condição essencial para compreender que saberes e conhecimentos são complementares.

No processo da fala e da escuta a disciplina do silêncio a ser assumida com rigor e a seu tempo pelos sujeitos que falam e escutam é um 'sine qua' da comunicação dialógica. O primeiro sinal de que o sujeito que fala sabe escutar é a demonstração de sua capacidade de controlar não só a necessidade de dizer a sua palavra, que é um direito, mas também o gosto pessoal, profundamente respeitável, de expressá-la (FREIRE, 1996: 60).

Mas o que é escutar o outro numa proposta afrodiaspórica? Não se trata de escutar para poder falar, nem tão pouco uma escuta eventual - sem preparação. Não se escuta com ouvidos de seus próprios argumentos objetivando reforçá-los. A escuta de que tratamos esta proposta por Ronaldo Só Moutinho,

O que se está se falando é de uma escuta que se abre em três naturalmente. A primeira implica na escuta do outro: que é um eu do outro lado e que está na presença de um eu ou de outros eus. A segunda é o desafio da auto-escuta, isto é, ao mesmo tempo em que escutamos, nos escutamos nos levando a nós mesmos: mistério de cada um. A terceira nos lança no silêncio revelador da 
linguagem. Linguagem aqui compreendida como aquela que vai além de um sistema gramatical. Aquela que se diz antes da palavra balbuciada. Aquilo que a mãe compreende no bebe antes dele falar. É o que não vem só com as palavras: a linguagem se presentifica antes de qualquer código (MOUTINHO, 2016: 7).

Nas sociedades líquidas (BAUMAN, 2001) onde a capacidade de comunicar vem se resumindo a capacidade de falar - e seus matizes: gritar, postar, twitar, lacrar... -, a escuta, parte essencial do processo comunicativo, precisa ser aprendida, praticada e ensinada. A experiência nas escolas vem nos mostrando que quanto mais jovem o discente, menor sua capacidade de escuta e maior sua necessidade de fala. Porém, não é uma condição exclusiva dos jovens, haja vista, os descaminhos que sociedades e governos passaram a vivenciar mundo a fora. A fala, postagem ou twitter que lacra, vira mito, e numa sociedade do "não diálogo" este é um aval para acessar lugares de fala e de poder - inclusive presidências ao sul e ao norte.

A escuta é uma competência adquirida no processo de formação humana que não se ensina obrigando o outro a se calar. Decorre desta compreensão a potência do provérbio "a orelha vai à escola todos os dias", pois aprender a escutar é algo que se realiza na prática cotidiana envolvendo diversas habilidades. Esta competência ao ser escolarizada, sistematizada, visa provocar habilidades essenciais, procuramos iniciar os licenciando em exercícios visando desenvolver três destas habilidades: a primeira habilidade é de empatia pelo Outro, ao despir-se de Si, olhar e ouvir o Outro - seu outro Eu; a segunda habilidade está ligada a concentração, num sistemático esforço de manutenção de foco, consistindo na captura de todas as linguagens envolvidas no processo comunicativo; e a terceira habilidade é a atenção, consistindo num processo de desnaturalização da escuta, assim, não se trata de uma escuta rotineira.

A escuta do Outro se abre em duas potências complementares: a primeira ao perceber esse Outro como parte do Eu estamos expressando nossa consciência da relação intrínseca entre o Eu e o Outro, ampliado na relação indivíduo e comunidade. Esta compreensão de mundo caracteriza o saber ubuntu - Umuntu Ngumuntu Ngabantu ${ }^{4}$ como ética a partir de uma afroperspectiva, nas palavras de Renato Noguera,

\footnotetext{
${ }^{4}$ Provérbio Zulu e Xhosa que significa: uma pessoa é uma pessoa através de outras pessoas.
} 
Ubuntu pode ser traduzido como "o que é comum a todas as pessoas". A máxima zulu e xhosa, umuntu ngumuntu ngabantu (uma pessoa é uma pessoa através de outras pessoas) indica que um ser humano só se realiza quando humaniza outros seres humanos. A desumanização de outros seres humanos é um impedimento para o autoconhecimento e a capacidade de desfrutar de todas as nossas potencialidades humanas. $\mathrm{O}$ que significa que uma pessoa precisa estar inserida numa comunidade, trabalhando em prol de si e de outras pessoas. A ideia de ubuntu atravessa, constitui e regula inúmeras comunidades africanas bantufonas (NOGUERA, 2012: 148).

\section{Um pouco de chuva a cada dia encherá os rios até transbordarem}

Com este novo olhar em construção, os discentes de estágio supervisionado e os discentes pibidianos adentraram por um formato virtualizado e mediado por um grupo no Whatsapp. Em paralelo a isso, as aulas com os estudantes do Ensino Médio e EJA, já estavam ocorrendo no ambiente virtual também devido à pandemia.

As turmas de primeiro ano do Ensino Médio e EJA, foram migradas para a virtualização a partir da segunda quinzena de março, o que permitiu um contato preliminar, garantindo a construção, ainda que embrionária, de uma relação de ensino/afeto, assim, além da plataforma oficial - Google Classroom - disponibilizada pela Seeduc-RJ, mas foi possível utilizar outras plataformas como o youtube, o anchor/spotify, o instagram e a principal delas o whatsapp.

Tanto pelos adolescentes do primeiro ano quanto pelos estudantes mais velho do EJA, ocorreu uma predileção pelo whatsapp que decorreu de três fatores articulados: primeiro, a prática de uso cotidiano por parte dos adolescentes com a ferramenta; segundo, o custo muito reduzido ou zerado em virtude do tipo de pacote de dados que cada um dos adolescentes possuía - muitas vezes o aplicativo vem liberado no pacote e assim não consome os dados de internet, bem diferente da plataforma disponibilizada pela Seeduc-RJ - e terceiro fator, a praticidade rápida de resposta e a liberdade que a plataforma promoveu de comunicação com a construção de grupos por turma. Ao todo, foram seis grupos (1 do EJA e 5 do primeiro ano do Ensino Médio), com uma média de trinta e cinco discentes em cada grupo, totalizando 216 discentes. 
Em virtude do tempo de maturação, os licenciandos chegaram após a realização das atividades diagnósticas ${ }^{5}$ - onde se percebeu que $47 \%$ dos discentes do Ensino Médio (com uma média de faixa etária de 16 anos e não trabalham), possuíam como trajetória escolar o programa carioquinha da rede municipal do Rio de Janeiro (SME-RJ) - logo, oriundos de um projeto de aceleração que busca corrigir distorções de idade/série, realizando a aceleração dos estudos cumprindo dois anos em um, assim, muitos conhecimentos acabam sendo deixados de fora do processo devido a dinâmica da proposta. No caso do EJA, os estudantes não concluíram seus estudos, de modo que o perfil etário dos estudantes-trabalhadores é acima de 30 anos.

Foi possível perceber entre a totalidade dos discentes do primeiro ano e do NERJA, que a maioria esmagadora, desconhecia ou não recordava das aprendizagens referentes à Cartografia básica e a História Antiga. Desta forma, o início das atividades buscou contemplar estes conhecimentos, muito embora, o Currículo Mínimo do Estado indicasse outro caminho. Assim, pode-se separar os licenciados entre as seis turmas foram organizadas para compreender histórico-geograficamente o mundo antigo. Buscou-se desenvolver as habilidades de reconhecimento, enunciação e definição, num primeiro momento. Posteriormente iriam desenvolver as habilidades de identificação, localização e transcrição, em um segundo momento.

Diante das informações obtidas pelo diagnóstico realizado e observando o planejamento para as turmas, dois discentes licenciandos, propuseram ${ }^{6}$ atividades pedagógicas para o desenvolvimento das habilidades e o conhecimento dos conteúdos cartográficos e históricos relacionados à Antiguidade. Suas propostas, ao serem discutidas no coletivo, receberam uma conotação decolonial investigativa, tendo como objeto de estudo o Egito Antigo.

A primeira consistia em buscar nos livros didáticos (que os discentes do Ensino Médio/EJA receberam antes do processo de virtualização, a partir do trabalho da coordenação e direção pedagógica do CEAPJ) a representação cartográfica do Egito - o mapa do Egito. Foi solicitado que reconhecessem e localizassem o Egito Antigo nos livros didáticos, que fotografassem e postassem nos grupos de whatsapp de cada turma.

\footnotetext{
5 Essa informação costuma ser realizada na sala de aula presencial. Todavia, o resultado desse diagnóstico é oriundo de um questionário preenchido no início das aulas dentro da plataforma virtualizada Google Classroom, em virtude da pandemia.

6 Tal proposta foi elencada no grupo que reúne todos os licenciados e posteriormente discutida em um encontro virtual pelo Meet para ser aplicado em todas as turmas.
} 
O resultado foi uma participação de $92 \%$ dos discentes da turma, gráfico 01, sendo que desses, $83 \%$ fotografaram imagens que representava o Egito Antigo e sua relação com as civilizações dos Rios Tigre e Eufrates, gráfico 02. Assim, eles haviam realizado a atividade de forma correta, pois pesquisaram e fotografaram a imagem que representavam o surgimento das grandes civilizações envolvendo os Rios Nilo, Tigre e Eufrates.

Gráfico 01: participação dos alunos em sala

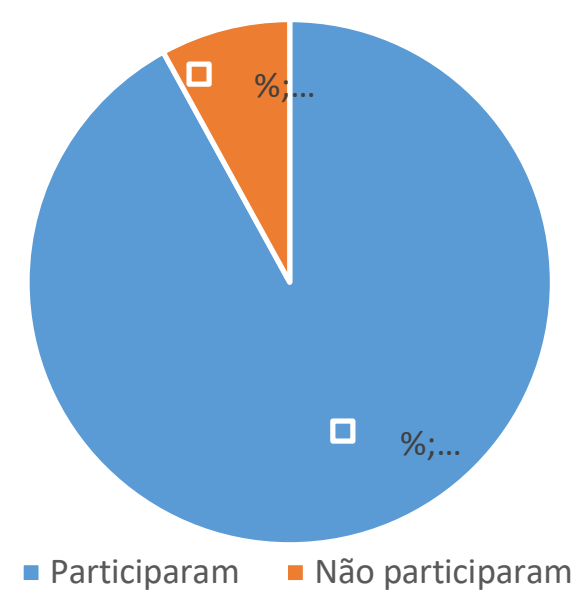

Fonte: Os autores.
Gráfico 02: Representação do Egito pelos alunos

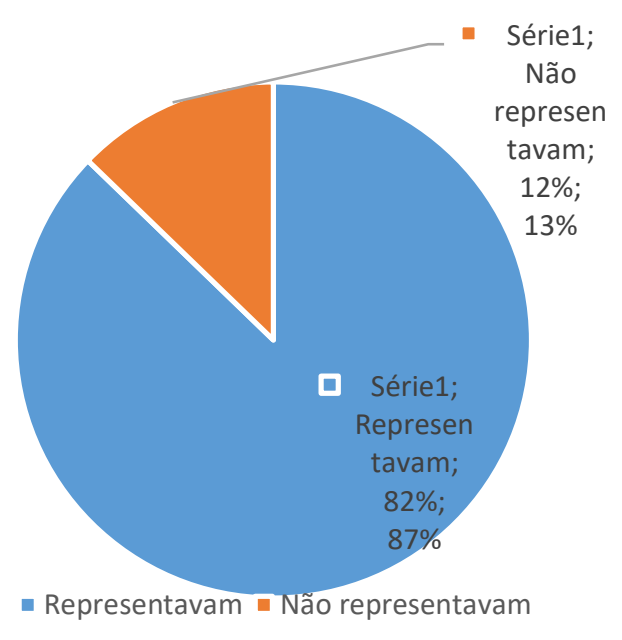

Fonte: Os autores.

Porém a sequência da atividade demonstrou um problema, pois ao serem indagados sobre o posicionamento geográfico do Egito, quase que a totalidade dos discentes responderam de forma equivocada: noventa e quatro por cento, respondeu que o Egito ficava situado na Ásia, três por cento respondeu na Europa, e três por cento respondeu na África, gráfico 03. 


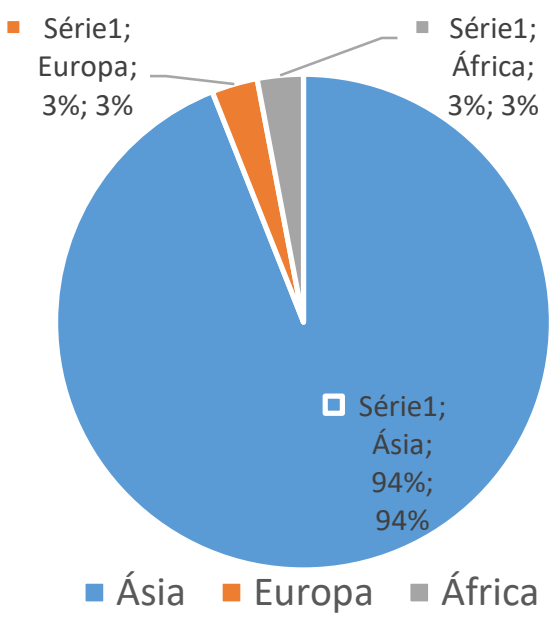

Fonte: Os autores.

Continuando em analisar as respostas entregues pelos alunos do Ensino Médio/EJA, foi solicitado que justificassem a indicação da posição geográfica, e as respostas apontaram dois caminhos para problematização: $61 \%$ respondeu que o Egito fazia parte da região do Oriente Médio, pois assim estava demonstrando no mapa; 33\% respondeu que o Egito ficava na Ásia por ser uma das grandes civilizações antigas, logo, não eram selvagens; $3 \%$ respondeu que o Egito Antigo estava situado na Europa por ser uma grande civilização; e 3\% afirmou ficar na África, pois o Egito Antigo ficava situado na África.

A segunda atividade proposta pelos discentes licenciandos, consistia em solicitar que os discentes do primeiro ano do Ensino Médio fossem divididos em dois grupos. O primeiro ficaria responsável por buscar na internet imagens de produções cinematográficas, que retratassem imageticamente a população egípcia do período estudado. O segundo grupo buscaria na internet em produções televisiva imagens da população do Egito antigo. Após a busca, coleta e seleção das imagens, os discentes do primeiro ano deveriam dialogar em seus grupos e postar apenas três imagens seguindo o critério de quais seriam as mais representativas. Posteriormente essas imagens foram organizadas pelos licenciandos e colocadas nos grupos juntamente com um formulário do google forms, para que indicassem aquela que mais representaria o Egito Antigo para cada um deles.

O resultado encontrado na atividade surpreendeu a todos os licenciandos envolvidos no processo de ensino-aprendizagem. Nas produções cinematográficas, a imagem mais representativa escolhida por eles foi: em primeiro lugar a personagem 
Cleópatra do filme Cleópatra (1963) interpretada pela atriz Elizabeth Taylor - escolhida por $72 \%$ dos discentes; em segundo lugar, a personagem Set interpretado por Gerard Butler no filme Deuses do Egito (2016) - escolhido por 17\% dos discentes; e em terceiro lugar, a personagem Moisés, interpretado Yul Brynner, no filme Os dez mandamentos (1956) - escolha de $11 \%$ dos discentes. Todas as personagens escolhidas eram interpretadas por atrizes e atores com fenotipagem étnica branca, figura 01.

As produções televisivas apresentaram resultado semelhante ao anterior. O primeiro lugar ficou com a personagem José, interpretado pelo ator Ângelo Paes Leme, na novela José do Egito (2013), da emissora Record - escolha de 87\% dos discentes. A segunda personagem foi Moisés, interpretado pelo ator Guilherme Winter, na novela: Os dez mandamentos (2015) da emissora Record. A terceira foi a personagem Merabe, interpretado pela atriz Camila Rodrigues, na novela Rei Davi (2012), também da emissora Record, figura 02.

\begin{tabular}{|c|c|c|}
\hline Figura 01: Representação dos personagens em filmes que tratam do Egito, apresentando o folder de \\
apresentação de cada filme. \\
\hline
\end{tabular}

Figura 02: Representação dos personagens em novelas que tratam do Egito, apresentando o folder de apresentação de cada filme. 


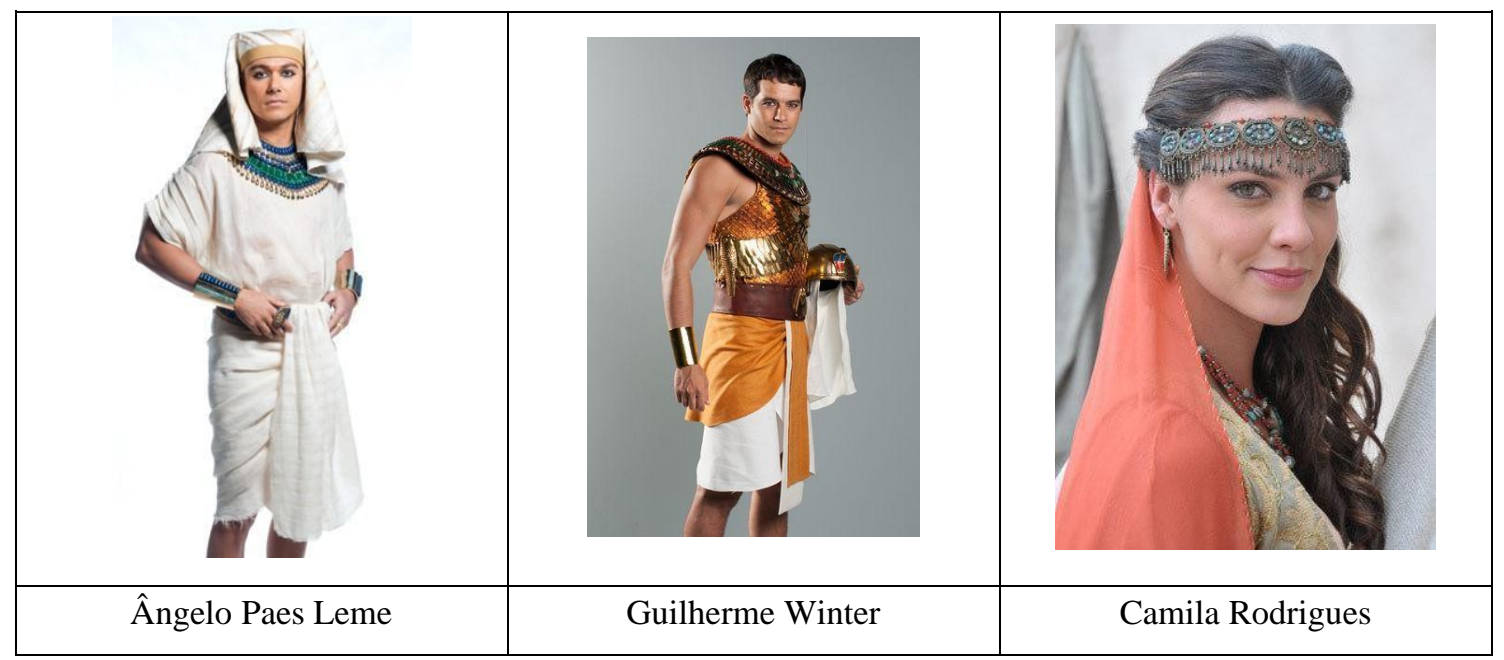

No google forms após a escolha das imagens mais representativas, foram colocadas duas perguntas fechadas (objetivas) sobre o Egito Antigo. A primeira, solicitando que os discentes identificassem etnicamente a população do Egito Antigo: $87 \%$ optou pela alternativa branco/europeu, $5 \%$ optou pela alternativa pardo/mestiço; $3 \%$ optou pela alternativa negro/africano; e 2\%, pela alternativa branco/africano, gráfico 04. A segunda pergunta sobre a localização do Egito Antigo produziu as seguintes respostas: 90\% apontou o Egito Antigo localizado na Europa; $7 \%$ apontou o Egito Antigo localizado na Ásia; e 3\% na África, gráfico 05.

Gráfico 04: Identificação étnica da população do

Egito Antigo pelos alunos em sala

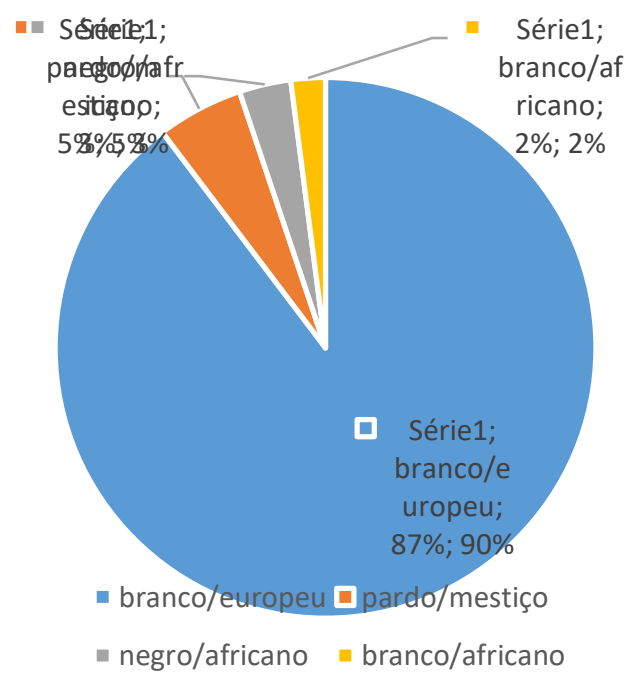

Fonte: Os autores.
Gráfico 05: Localização geográfica do Egito pelos alunos em sala

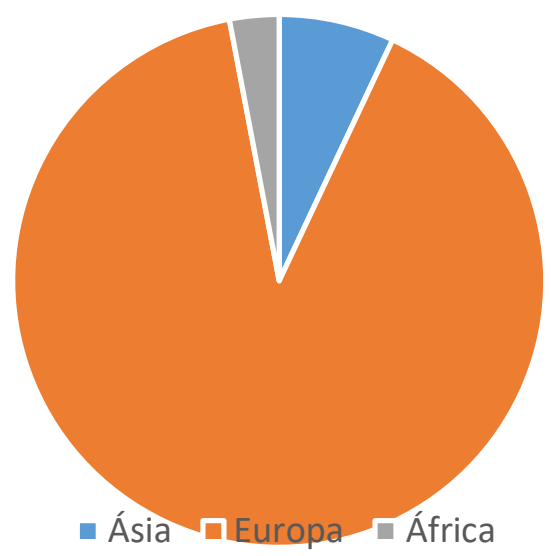

Fonte: Os autores. 
As atividades realizadas pelos discentes do Ensino Médio levaram os licenciandos a refletirem sobre o carrego euro-colonialista que a educação num sentido amplo contemplando a escolar e a realizada pelo complexo cultural (cinema-televisão), estavam fomentando como representação do mundo. A representação construída através do livro didático situava o Egito Antigo na Ásia, já a representação do cinema e da televisão indicava a Europa.

Em relação à população do Egito Antigo a maioria esmagadora os representava como pessoas brancas por ser uma grande civilização ou pelas personagens que os representava. Essa atividade levou os licenciando a refletirem sobre a construção social realizada sobre o Egito Antigo e suas representações. Uma construção diversificada como as chuvas, que lentamente formavam um complexo ideário que deslocava o Egito da África e apagava a relação desta grande civilização com a população negra que a compunha, formando uma compreensão equivocada colonialista sobre esta temática - um rio que transborda ignorância e preconceito.

Desta maneira, percebe-se que as vivências realizadas na escola, mesmo que em um processo de aulas virtuais, pelo olhar docente (supervisor e preceptor), durante a formação docente dos licenciandos que realizaram estágio e PIBID na virtualização do CEAPJ, nos remeteram às reflexões sobre o processo formativo acadêmico e sua relação com a sociedade na qual estes novos docentes irão atuar.

Em relação às reflexões, um primeiro ponto perceptível estava ligado a uma "certa ansiedade" dos licenciandos em transmitir o conhecimento adquirido em suas formações. Ansiedade essa, que consistia em despejar sobre os discentes de Ensino Médio seu cabedal teórico - autores e teorias, associados à preocupação com o pouco tempo de aula disponível para as disciplinas de Geografia e História.

Porém, esta "ansiedade" e preocupação, não permitiu que compreendessem o duplo sentido do processo de ensino-aprendizagem - talvez por uma formação que ainda careça em articular de forma intradisciplinar a teoria das áreas específicas e a pedagogia da práxis docente - pois escapava a eles que este é um processo dialógico, comunicativo, de escuta em todos os sentidos.

Uma segunda reflexão esteve direcionada para a importância das Leis 10.639/2003 e 11.645/2008, num contexto de políticas afirmativas. A quase totalidade dos licenciandos reconhecia a importância destas leis num País marcado pelas desigualdades sociais e o racismo. Muitos afirmavam categoricamente estarem dispostos 
a trabalhar no combate a perpetuação desta mácula social, porém, poucos estudantes sabiam como colocar este desejo no chão da escola, dificuldade essa que aumentou por estar em um contexto de virtualização. Os poucos que afirmavam ter domínio para execução desta tarefa, se valeram das leituras acadêmicas, que traziam uma discussão pertinente para formação do docente, mas pouco exequível na educação básica, outros, reproduziam materiais didáticos que carregavam, ainda hoje, distanciamentos e distorções dos conhecimentos sobre África.

A terceira reflexão está relacionada à aplicação das Leis sobre ensino da cultura e da história de África, africanidades e indígenas nas Licenciaturas. Uma percepção que compartilhamos é que inúmeras vezes o foco recai sobre a educação básica e a formação continuada dos docentes, que já estão no mercado de trabalho - possível perceber pela necessária proliferação de cursos de pós-graduação lato e stricto sensu, voltadas para temática, sendo alguns de excelência teórica e prática. Porém, ao observarmos as matrizes de formação dos novos docentes percebemos em sua grande maioria uma adaptabilidade às Leis, quase uma resposta que se limita a apresentar de forma concisa algumas histórias e práticas culturais africanas, afrodescendentes e indígenas. Raros são os casos em que a história e a cultura africana, afrodescendente e indígena são pensadas endocentricamente, a partir da perspectiva própria deste, ou seja, o olhar lançado sobre essas histórias e culturas são o olhar euro-colonialista.

Este entendimento anterior nos lança a uma quarta e urgente reflexão. É preciso, ao lado do pensamento euro-colonialista, edificar um pensamento decolonial que revele outros olhares, outros paradigmas e assim possa ofertar uma encruzilhada entre conhecimentos e saberes. Uma perspectiva que potencialize a construção de pedagogias decoloniais, como as apresentadas por Nei Lopes, Luiz Antonio Simas, Conceição Evaristo, Luiz Rufino, Allan da Rosa, Ronaldo Só Moutinho, Renato Noguera, Paulo Freire e outros que nos precederam ou caminham conosco. Para isso é preciso levar autores decolonialistas para leitura de formação docente, de forma que permeie os conhecimentos específicos e pedagógicos.

\section{Ninguém testa a profundidade de um rio com ambos os pés}


As primeiras conclusões que extraímos desta vivência nos remeteram a reafirmação da compreensão do distanciamento, ainda hoje, entre a academia universitária e o chão da escola pelo viés virtual. Deriva daí a importância de um estágio supervisionado que vá além da mera observação, e principalmente, das políticas públicas de qualificação dos licenciando através da CAPES - PIBID e Residência Pedagógica. Quanto mais cedo o licenciando vivencia essa prática pedagógica na escola, mais cedo ele compreende o dialogismo do processo de ensino-aprendizagem. Como nos ensina o provérbio africano, é preciso conhecer a profundidade do rio colocando um dos pés nele, logo, é preciso conhecer as dinâmicas escolares estando com o pé no chão da escola.

Assim, pode-se potencializar ações autorais dos licenciandos ao trazerem propostas para as turmas do Ensino Médio/EJA e tais sugestões permitiu compreender um colonialismo do saber em que domina o imaginário dos estudantes da Educação Básica ao pensar em um povo não europeu, mas com toda uma característica e estereótipo ocidental, isto é, branco, caucasiano e dos olhos azuis, diferente das características étnicas de uma sociedade localizada ao Norte da África. Com isso, pode-se constatar ainda a mudança de opinião dos estudantes da Educação Básica em relação a localização do Egito, pois foi perguntada duas vezes e houve uma mudança do pensamento ao trazer o imaginário dos filmes/novelas, demonstrando também como o senso comum vai construindo toda uma forma de pensar desses alunos.

Vale dizer que um dos principais desafios, em um contexto de pandemia, a foi conseguir motivar os estudantes do Ensino Médio/EJA para participarem das aulas, pois sem esse protagonismo deles, não seria possível que os estudantes universitários vivenciassem tais práticas pedagógicas em sua formação inicial.

Outra conclusão que chegamos é a urgência de adentar a mata do pensamento decolonial e expô-lo! Colocá-lo num lugar de destaque nos processos formativos de licenciandos e na formação continuada dos docentes já nas redes escolares. Só a partir do espraiamento do pensamento decolonial será possível sair da marafunda do pensamento euro-colonialista, e assim, adentramos numa nova fase da práxis docente, potencializando a formação de novos intelectuais orgânicos que vejam conhecimentos e saberes sob outras perspectivas, em cruzo. Só assim, a esperança poderá ser o pilar do mundo!

\section{Referências bibliográficas}

BALLESTRIN, Luciana Maria de Aragão (2017). Modernidade / Colonialidade sem "Imperialidade"? O Elo Perdido do Giro Decolonial. Dados, Rio de Janeiro, v. 60, 
n. 2: 505-540,

abril. Disponível

em

$<$ http://www.scielo.br/scielo.php?script=sci_arttext\&pid=S0011-

$52582017000200505 \& \operatorname{lng}=$ en\&nrm=iso $>$. acesso em 12 de fevereiro de 2021. http://dx.doi.org/10.1590/001152582017127.

BAUMAN, Zygmunt (2001). Modernidade Líquida. Rio de Janeiro: Zahar.

BENJAMIN, H. R. W. (1939). Saber-tooth curriculum, including other lectures in the history of paleolithic education. New York: McGraw- Hill.

BITTENCOURT, Circe Fernandes (2018). Reflexões sobre o ensino de História. Estud. av., São Paulo, v. 32, n. 93: 127-149, agosto. Disponível em <http://www.scielo.br/scielo.php?script=sci_arttext\&pid=S010340142018000200127\&lng=en\&nrm=iso>. acesso em 12 de fevereiro de 2021. http://dx.doi.org/10.5935/0103-4014.20180035.

BOURDIEU, Pierre (1989). O poder simbólico. Rio de Janeiro: Bertrand.

FAORO, Raymundo (2001). Os donos do poder. Formação do patronato político brasileiro. Rio de Janeiro: Globo.

FREIRE, P. (2001). A educação na cidade. São Paulo: Cortez. (1996). Observação, registro e reflexão. Instrumentos metodológicos I. São Paulo: Espaços Pedagógicos. (1982). Educação: o sonho possível. In. BRANDÃO, C. R. (org.). O educador: vida e morte. Rio de Janeiro: Graal: 89-101.

GROSFOGUEL, Ramon (2008). Para Descolonizar os Estudos de Economia Política e os Estudos Pós-coloniais: Transmodernidade, Pensamento de Fronteira e Colonialidade Global. Revista Crítica de Ciências Sociais, n. 80.

HALL, Stuart (1997). A centralidade da cultura: notas sobre as revoluções culturais do nosso tempo. Cultura, Mídia e Educação - Educação \& Realidade. Porto Alegre, v. 22, n 2: 15-46, jul./dez.

KOSELLECK, Reinhart (1992). Uma história dos conceitos: problemas teóricos e práticos. Estudos Históricos. Rio de Janeiro, vol. 5, n. 10: 134-146.

LUCKESI, C. C. (1990). Filosofia do cotidiano escolar: por um diagnóstico do senso comum. In: Filosofia da educação. São Paulo: Cortez.

MIGNOLO, Walter (2005). A colonialidade de cabo a rabo: o hemisfério ocidental no horizonte conceitual da modernidade. In: LANDER, E. (Org.). A colonialidade do saber: eurocentrismo e ciências sociais. Perspectivas latino-americanas. Buenos Aires: Clacso: 71-103.

MOUTINHO, Ronaldo Só (2016). Escuta: legado afrodescendente e seus desafios. Revista África e Africanidades, Ano 9, n. 21, jan-abr. Disponível em: https://africaeafricanidades.net/documentos/0010210042016.pdf. Acesso em 11 fev. 2021

NOGUERA, Renato (2012). Ubuntu como modo de existir: elementos gerais para uma ética afroperspectivista. Revista da $A B P N$. Uberlândia: ABPN, v.3, n.6, nov-fev: 147-150. Disponível em: https://filosofiaafricana.weebly.com/uploads/1/3/2/1/13213792/renato_noguera__ubuntu_como_modo_de_existir.pdf Acesso em $11 \mathrm{fev}, 2021$.

OLIVEIRA, Luiz Fernandes de; CANDAU, Vera Maria Ferrão (2010). Pedagogia decolonial e educação antirracista e intercultural no Brasil. Educ. rev., Belo Horizonte, v. 26, n. 1: 15-40, abril. Disponível em $<$ http://www.scielo.br/scielo.php?script=sci_arttext\&pid=S010246982010000100002\&lng=en\&nrm=iso >. acesso em 12 de fevereiro de 2021. http://dx.doi.org/10.1590/S0102-46982010000100002. 
QUIJANO, Aníbal (2007). Colonialidad del poder y clasificación social. In: CASTROGÓMEZ, S.; GROSFOGUEL, R. (Orgs.). El giro decolonial. Reflexiones para uma diversidad epistémica más allá del capitalismo global. Bogotá: Universidad Javeriana-Instituto Pensar, Universidad Central-IESCO, Siglo del Hombre Editores: 93-126.

QUIJANO, Aníbal (2005). Colonialidad del poder, eurocentrismo y América Latina. In: LANDER, E. (Org.). La colonialidad del saber: eurocentrismo y ciencias sociales. Perspectivas Latinoamericanas. Buenos Aires: Clacso: 227-277.

RIBEIRO, Darcy (2002). O Povo Brasileiro. A formação e o Sentido do Brasil. São Paulo: Companhia das Letras.

ROCHA, G.O.R. (1997). A trajetória da disciplina geografia no currículo escolar brasileiro (1837-1942). In: 6 ENCUENTRO DE GEÓGRAFOS DE AMÉRICA LATINA, 1997, Buenos Aires. CDROOM - RESÚMENES. Buenos Aires: Universidad de Buenos Aires.

ROCHA, G.O.R. (1996). A trajetória da disciplina geografia no currículo escolar brasileiro (1837 - 1942). (Dissertação de Mestrado), Pontifícia Universidade Católica de São Paulo, São Paulo.

RUFINO, Luiz (2019). Pedagogia das encruzilhadas. Rio de Janeiro: Mórula.

SANTOS, Milton (2008). Técnica, espaço, tempo: globalização e meio técnicocientífico-informacional. 5. ed. São Paulo: Edusp. (2012). A natureza do espaço: técnica e tempo, razão e emoção. 4. ed. São Paulo: Edusp.

SOUZA, Marcelo Lopes (2012). O território: sobre espaço e poder, autonomia e desenvolvimento. In: CASTRO, I. E. (Orgs.). Geografia: conceitos e temas. 15. ed. Rio de Janeiro: Bertrand Brasil.

WALSH, Catherine (2006). Interculturalidad y colonialidad del poder. Un pensamiento y posicionamiento 'otro' desde la diferencia colonial". In: WALSH, C.; LINERA, A. G.; MIGNOLO, W. Interculturalidad, descolonización del estado y del conocimiento. Buenos Aires: Del Signo: 21-70. (2005). Introducion - (Re)pensamiento crítico y (de)colonialidad. In: WALSH, C. Pensamiento crítico y matriz (de)colonial. Reflexiones latinoamericanas. Quito: Ediciones Abya-yala: 13-35.

Artigo recebido em 14 de fevereiro de 2021.

Artigo Aprovado em 07 de junho de 2021.

DOI: $10.12957 /$ intellectus.2021.57779 